\title{
sensors
}

ISSN 1424-8220

(C) 2007 by MDPI

www.mdpi.org/sensors

Full Research Paper

\section{PVC Membrane Sensors for Potentiometric Determination of Acebutolol}

\author{
Gamal Abdel-Hafiz Mostafa *, Mohamed Mahmoud Hefnawy and Abdulrahman Al-Majed \\ Pharmaceutical Chemistry Department, College of Pharmacy, King Saud University, P.O.Box 2457, \\ Riyadh11451, Saudi Arabia.
}

*Corresponding Author. E-mail: gamal_most@yahoo.com

Received: 11 July 2007 / Accepted: 8 October 2007 / Published: 13 December 2007

\begin{abstract}
The construction and general performance characteristics of two novel potentiometric membrane sensors responsive to the acebutolol are described. The sensors are based on the use of ion-association complexes of acebutolol (AC) with tetraphenylborate(TPB) (I) and phosphomolybdate(PM) (II) as exchange sites in a PVC matrix. The sensors show a fast, stable and near- Nernstian for the mono charge cation of $\mathrm{AC}$ over the concentration range $1 \times 10^{-3}-\sim 10^{-6} \mathrm{M}$ at $25^{\circ} \mathrm{C}$ over the $\mathrm{pH}$ range 2.0 6.0 with cationic slope of $51.5 \pm 0.5$ and $53.0 \pm 0.5$ per concentration decade for AC-I and AC-II sensors respectively. The lower detection limit is $6 \times 10^{-6} \mathrm{M}$ and $4 \times 0^{-6} \mathrm{M}$ with the response time 20-30 s in the same order of both sensors. Selectivity coefficients of $\mathrm{AC}$ related to a number of interfering cation and some organic compounds were investigated. There are negligible interferences are caused by most of the investigated species. The direct determination of $3-370 \mu \mathrm{g} / \mathrm{ml}$ of AC shows an average recovery of 99.4 and $99.5 \%$ and a mean relative standard deviation of $1.5 \%$ at $100.0 \mu \mathrm{g} / \mathrm{ml}$ for sensor I and II respectively. The results obtained by determination of AC in tablets using the proposed sensors which comparable favorably with those obtained by the British pharmacopoeia method. In the present investigation the electrodes have been utilized as end point indicator for some precipitation titration reactions.
\end{abstract}

Keywords: Acebutolol, Sodium tetraphenylborate, Phosphomolybdic acid, PVC, Potentiometry. 


\section{Introduction}

Acebutolol hydrochloride, (Fig.1.) is a cardioselective, hydrophilic $\beta$-adrenoreceptor blocking agent with mild intrinsic sympathomimetric activity for use in treating patients with hypertension and ventricular arrhythmias. It is marketed in tablets form for oral admininistration [1].

Different techniques have been concerned with the development of rapid and sensitive methods for the separation, identification or determination of $\mathrm{AC}$ and several others $\beta$-blockers. Those techniques are high performance liquid chromatography (HPLC)[2,3], HPLC-mass spectrometry(MS)[4], gas chromatography-mass spectrometry (GC-MS)[5], and capillary electrophoresis (CE) [6] were presented for the sensitive detection of the $\beta$-blocking agents in human urine. On the other hand,<smiles>CCCC(=O)Nc1ccc(OCC(O)CNC(C)(Cl)Cl)c(C(C)=O)c1</smiles>

Figure 1.Chemical structure of acebutolol hydrochloride.

existing publications concerning the individual determination of $\mathrm{AC}$ in pharmaceutical preparations were based on, spectrophotometry [7-10], spectrofluorimetry [8], thin layer chromatography (TLC)[9], polarography [11], HPLC [9,10,12], GC[10] and CE[13].

Since, some of these methods required expensive equipment(s) and/or especial treatment. Potentiometric membrane sensors have been more extensively used in pharmaceutical analysis. Their advantages are simple design, low cost, adequate selectivity, low detection limit, high accuracy, wide concentration range, applicability to colored; turbid solution and have found wide applications in divers field of analysis[14-17]. To our knowledge no potentiometric electrochemical sensors has been yet described for determination of AC. The only reported method is a coated wire electrode for some $\beta$-blocker and calcium blocker has been suggested based on the use of dinonylnaphthaline sulphonic acid as ion exchanger material. Their selectivity behavior was accurately predicted from calculated distribution coefficient constant for each drug [18] (acebutolol one of them). The present work describes the construction and evaluation of novel PVC membrane sensors for $\mathrm{AC}$ in its pharmaceutical preparations. The sensitivity and stability offered by the PVC sensors are in advantageous to allow accurate determination of low levels of AC.

\section{Results and Discussion}

\subsection{Sensor characteristics}

AC readily reacts with NaTPB and PMA solution to form a sparingly soluble ion associate complex of 1:1 and 3:1 for AC: TPB and AC: PM respectively. Plastic membranes were prepared by using a 
casting solution of the composition 1.82: 34.54: $63.64(\mathrm{w} / \mathrm{w})$ ion associates, PVC and dioctylphthalte (DOP) or dibutyl phthalate (DBP) or tricresyl phosphate (TCP) or dibutylsebacate (DBS) or onitrophenyloctyl ether (o-NPOE) as plasticizers, respectively. The potentiometric response for AC based on the use of AC-TPB or AC-PM ion pair complexes as a novel electroactive material and oNPOE as a plasticizer in a PVC matrix were evaluated according to IUPAC recommendations [19], oNPOE showed better performance characteristics. The elemental analysis data agree with the composition of 1:1 and 3:1 for AC: TPB and AC: PMA respectively. From IR spectra both ion-associate complexes showed the observed bands at $2910 \mathrm{~cm}^{-1}$ and $3000 \mathrm{~cm}^{-1}$ indicate $\mathrm{CH}$ starching aliphatic and aromatic respectively; two bands at $3205 \mathrm{~cm}^{-1}$ and $3340 \mathrm{~cm}^{-1}$ indicate the presence of $\mathrm{NH}$ and $\mathrm{OH}$ group. Also the observed band at $1590 \mathrm{~cm}^{-1}$ indicates the presence of carbonyl group. There were no absorption bands in case of PMA or NaTPB reagent. They concluded that, the formation of ion-associate complexes. The performance characteristics of the electrode in o-NPOE are given in Table 1. In phosphate buffer of $\mathrm{pH} 4.0$, the sensor displays a linear and stable response for $1 \times 10^{-3}-8 \times 10^{-6} \mathrm{M}$; $1 \times 10^{-3}-6 \times 10^{-6} \mathrm{M}$ for $\mathrm{AC}$ with cationic slope of $51.5 \pm 0.5$ and $53.0 \pm 0.5 \mathrm{mV} / \mathrm{decade}$, and lower limit of detection being $6 \times 10^{-6} \mathrm{M}$ and $4 \times 10^{-6} \quad(\sim 2.3$ and $1.5 \mu \mathrm{g} / \mathrm{ml})$ for AC-TPB and AC-PM sensors respectively. The least squares equation obtained from the calibration data as follow:

$$
\begin{aligned}
& \mathrm{E}(\mathrm{mV})=(51.5 \pm 0.5) \log [\mathrm{AC}]+(134.0 \pm 0.5) \text { for sensor-I } \\
& \mathrm{E}(\mathrm{mV})=(53.0 \pm 0.5) \log [\mathrm{AC}]+(164.0 \pm 0.5) \quad \text { sensor-II }
\end{aligned}
$$

Table. 1. Response characteristics of the PVC membrane sensors.

\begin{tabular}{lcc}
\hline Parameter & \multicolumn{2}{c}{ Value* $^{*}$} \\
& $A C-T P B$ & $A C-P M$ \\
Slope, $(\mathrm{mV} /$ decade) & $51.5 \pm 0.5$ & $53.0 \pm 0.5$ \\
Intercept, $\mathrm{mV}$ & $134.0 \pm 0.5$ & $164.0 \pm 0.5$ \\
Correlation Coefficient, $(\mathrm{r})$ & 0.998 & 0.999 \\
Detection limit, $\mathrm{M}$ & $6 \times 10^{-6}$ & $4 \times 10^{-6}$ \\
Response time for $1 \times 10^{-3} \mathrm{M}$ solution, $\mathrm{s}$ & $25 \pm 0.5$ & $20 \pm 0.6$ \\
Working $\mathrm{pH}$ range & $2-6.0$ & $2-6.0$ \\
\hline * Average offive replicates &
\end{tabular}

\subsection{Response mechanism of the proposed sensor.}

The mechanism of potential response of most liquid and liquid polymeric membrane sensor is based on ion exchange equilibrium and analyte extraction process at the membrane interface. The membranes frequently contain hydrophobically trapped, mobile sites [19] in plasticized poly (vinyl chloride). Such membranes with charged sites are named sited membranes. Ions of opposite sign in the membrane are counter ions. Ions of the same sign as sites are not present in significant quantities are known as coions. Sited membranes are selective to counter ion i.e only counter ions exchange into the membrane and therefore have some mobility in the membrane bulk. 


\subsection{Effect of $p H$}

The effect of $\mathrm{pH}$ of the AC test solutions $\left(1 \times 10^{-3}, 1 \times 10^{-4}\right.$ and $\left.1 \times 10^{-5} \mathrm{M}\right)$ on the sensor potential was investigated by following the potential variation over the $\mathrm{pH}$ range 1-12. The electrode response for $\mathrm{AC}$ concentrations was tested by various $\mathrm{pH}$ values, each time being adjusted by using hydrochloric acid and sodium hydroxide solution. Potential-pH plots (Fig.1) reveal that, within $\mathrm{pH}$ range 2-6, the potential did not vary by more than $\pm 0.5 \mathrm{mV}$. At $\mathrm{pH}<2$ potential displayed by the sensors increased due to increasing the acid nature of the drug or interferences by hydrogen ion. At $\mathrm{pH}>7.0$, the potential displayed by the sensor sharply decreases due to formation of non-protonated acebutolol, the $\mathrm{pKa}$ value of $\mathrm{AC}=9.4$ (secondary aliphatic amine group) [20]. On the other hand upon testing different types of buffer

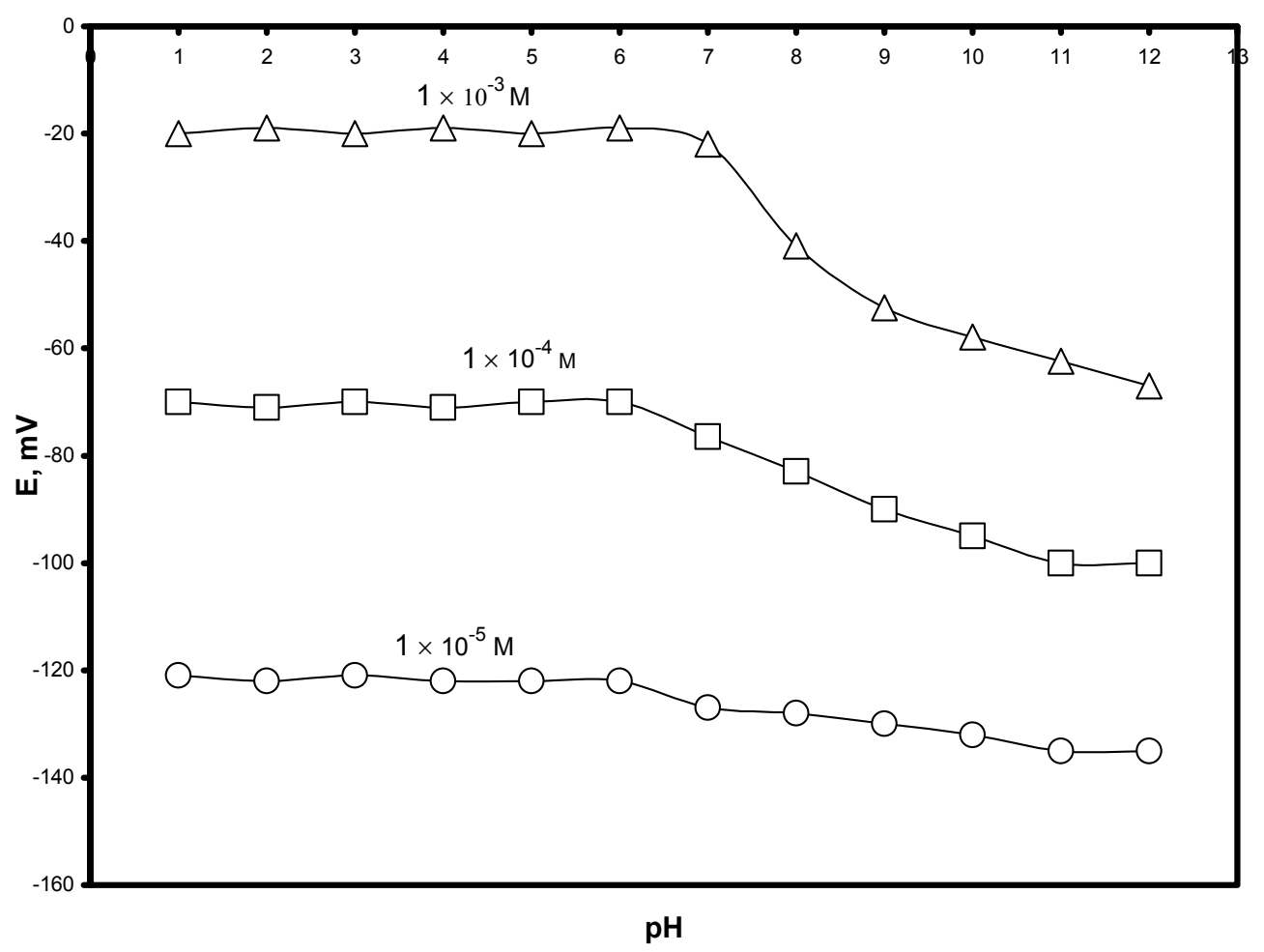

Figure 2.a. Effect of $\mathrm{pH}$ on the response of AC-PM membrane sensor using three series of AC solution $1 \times 10^{-3}, 1 \times 10^{-4}$ and $\left.1 \times 10^{-5} \mathrm{M}\right)$. 


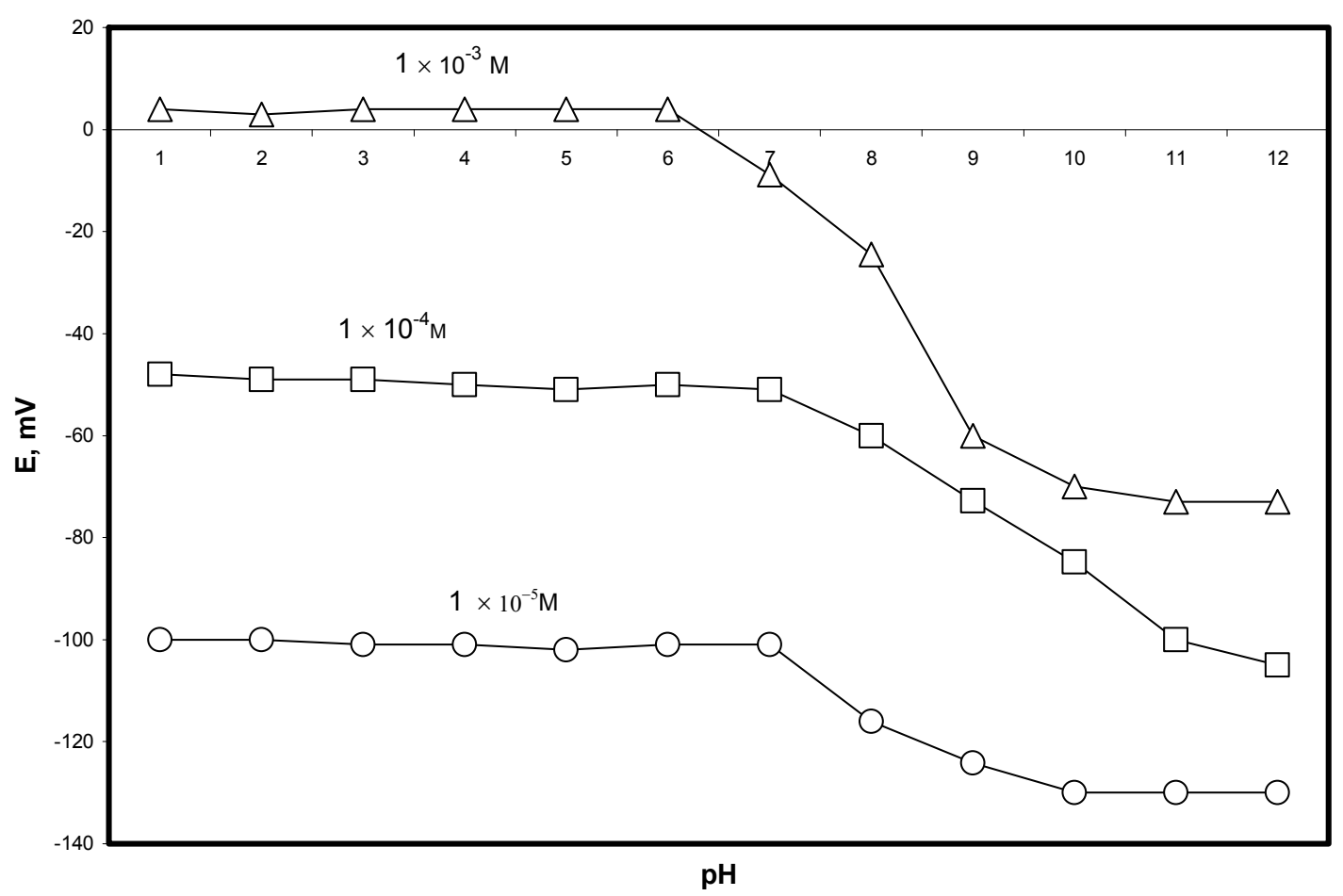

Figure 2.b. Effect of $\mathrm{pH}$ on the response of AC-PM membrane sensor using three series of AC solution $1 \times 10^{-3}, 1 \times 10^{-4}$ and $\left.1 \times 10^{-5} \mathrm{M}\right)$.

solution e.g. citrate, phthalate, phosphate and acetate in the suitable $\mathrm{pH}$ range of the membrane sensor, phosphate buffer ( $\mathrm{pH}$ 4.0) proved to be a more suitable measuring solution. All subsequent potentiometric measurements were made in phosphate buffer of $\mathrm{pH} 4.0$.

\subsection{Response time}

The average response time is defined as the time required for the electrode to reach a steady potential values within $\pm 1 \mathrm{mV}$ of the final equilibrium value, after successive immersion of the electrode in AC solutions each having a 10-fold difference, or after rapid 10-fold increase in concentration by the addition of $\mathrm{AC}$. This time was found to be short, ranging form $15 \mathrm{sec}$ for concentration $\geq 1 \times 10^{-4} \mathrm{M}$ and $20 \mathrm{sec}$ for concentration $\leq 1 \times 10^{-4} \mathrm{M}$.

The sensors displayed constant potential readings $\pm 1 \mathrm{mV} /$ concentration decade from day-today and the calibration slopes did not change by more than $2 \mathrm{mV} /$ concentration decade over a period of 4 weeks for both sensors, after which the membrane of the electrode should be renewed. The higher stability of the sensors is attributed to the increased lipophilicity of PM: TPB and this leads to partial leaching of the components from membrane sensors. After more than one month, a new section from the master membranes was found to function very properly. Table 2 shows the day-to-day reproducibility of the sensors. 
Table 2. Day to day reproducibility of the proposed method.

\begin{tabular}{ccccc}
\hline Parameter & \multicolumn{2}{c}{$A C(100 \mu \mathrm{g} / \mathrm{ml})^{*}$} & \multicolumn{2}{c}{$A C(100 \mu \mathrm{g} / \mathrm{ml})^{*}$} \\
& \multicolumn{2}{c}{ Within-day } & \multicolumn{2}{c}{ Between-days } \\
& $A C-T P B$ & $A C-P M$ & $A C-T P B$ & $A C-P M$ \\
R, \% & 98.0 & 98.7 & 97.7 & 98.5 \\
R.S. D, \% & 1.5 & 1.5 & 1.6 & 1.5 \\
Slope & $51.5 \pm 0.5$ & $53.0 \pm 0.5$ & $51.5 \pm 0.6$ & $53.0 \pm 0.6$ \\
Correlation coefficient & 0.998 & 0.999 & 0.998 & 0.998 \\
\hline
\end{tabular}

* Average of 5 measurements \pm RSD.

$* \mathrm{R} \%$, recovery percentage; RSD relative standard deviation

\subsection{Effect of plasticizer type on the characteristic performance of the sensor}

The effect of plasticizer composition was studied on the characteristic performances of AC-PVC membrane sensors. PVC membrane sensors were prepared using different plasticizers namely DBS, DOP, DBP, TCP and NPOE of different polarities which are usually used for the preparations of PVC membrane sensors. Sensors incorporated membranes plasticized with DOP, DBP, and TCP showed less response (slope 35, 29, $23 \mathrm{mV} /$ decade) for acebutolol probably due to poor solubility of ionassociate in the plasticizer. In case of DBS a negligible or very poor response was obtained. The solubility of the complex was examined by its ability to form transparent solution in the plasticizer. In case of NPOE a clear transparent solution was formed whereas in DOP, DBP, TCP and DBS turbid and suspended solutions were obtained, respectively. This indicate that the complex solubility in the order of NPOE $>$ DOP $>$ DBP $>$ TCP $>$ DBS. It seems that o-NPOE improves the membrane selectivity due to its high dielectric constant $(\varepsilon=24)$, affects considerable dissolution of ion-association within the membrane; consequently enhances its partition coefficient in the membrane and also provided suitable mechanical property of the membrane compared with less permittivity plasticizers.

\subsection{Effect of divers ions}

The potentiometric selectivity coefficient $K_{A, B}^{p o t}$ of an ISE is commonly used as quantitative expression of the ability of the electrode to respond primarily to the analyte ion in the presence of interfering ions. The influence of the presence of some different species on the response of AC sensors was investigated. The selectivity coefficients $K_{A, B}^{P o t}$ of the proposed sensors were calculated in the presence of related organic and inorganic substances using separate solution and mixed solution technique [21,22]. The selectivity coefficient $K_{A, B}^{p o t}$ measured by separate solution method was calculated from the following equation: 


$$
\log K_{A, B}^{p o t}=\mathrm{E}_{\mathrm{B}}-\mathrm{E}_{\mathrm{A}} / \mathrm{S}+\left[1-\mathrm{Z}_{\mathrm{A}} / \mathrm{Z}_{\mathrm{B}}\right] \log \mathrm{a}_{\mathrm{A}}
$$

Where $K_{A, B}^{\text {pot }}$ is the potentiometric selectivity coefficient; $\quad \mathrm{E}_{\mathrm{A}}$ and $\mathrm{E}_{\mathrm{B}}$ are the potential readings observed after $1 \mathrm{~min}$ of exposing the sensor to the same concentration of $\mathrm{AC}$ and interfering species $\left(1 \times 10^{-3}\right.$ each) alternatively, $a_{A}$ the activities or concentration of $A C ; Z_{A}$ and $Z_{B}$ are the charge of acebutolol and interfering ions and $S$ is slope of calibration graph ( $\mathrm{mV} /$ decade). The selectivity coefficient by mixed solution method was defined as the activity ratio of primary and interfering ions that give the same potential change under identical conditions. The selectivity coefficient $K_{A, B}^{\text {pot }}$ measured by mixed solution method was calculated from the following equation:

$$
K_{A, B}^{p o t}=\left(\mathrm{a}^{\prime}{ }^{-}-\mathrm{a}_{\mathrm{A}}\right) / \mathrm{a}_{\mathrm{B}}
$$

where $\mathrm{a}_{\mathrm{A}}$ known activity of primary ion, $\mathrm{a}_{\mathrm{A}}$ fixed activity of primary ion and $\mathrm{a}_{\mathrm{B}}$ activity of interfering ions. The results are given in Table 3 . The results reveal reasonable selectivity for AC in presence of many related substances.

\subsection{Validity of the proposed method}

\subsubsection{Limit of quantification and limit of detection}

Each of different concentration of standard solution was tested five times. The potentials obtained for the five analyses were averaged at each concentration. The average potential was plotted versus concentration. The relation between potential and concentration is logarithmic (equation 1 and 2) $x=s$ $\log [\mathrm{AC}]+y$ where $x$ is equal the potential, $s$ is the slope, and $y$ is the intercept and correlation coefficient $\mathrm{r}$ equal 0.998 and 0.999 , it is observed a linear (linear range) over the concentration range of $1 \times 10^{-3}-8 \times 10^{-6} \mathrm{M}$ and $1 \times 10^{-3}-6 \times 10^{-6} \mathrm{M}$ for AC-TPB and AC-PM respectively. The limits of detection (LOD) and limits of quantification (LOQ) were determined using the formula: LOD or LOQ $=k \mathrm{~S} . \mathrm{D} . \mathrm{a} / \mathrm{b}$, where $\mathrm{k}=3$ for LOD and 10 for LOQ, S.D.a is the standard deviation of the intercept, and $\mathrm{b}$ is the slope. Also lower limit of detection (LOD) defined as the concentration of AC corresponding to the intersection of the extrapolated linear segment of the calibration graph which is $6 \times 10^{-6} \mathrm{M}$ and $4 \times 10^{-6}(2.3$ and $1.5 \mu \mathrm{g} / \mathrm{ml})[19]$ for sensor-I and sensor-II respectively. 
Table 3. Potentiometric selectivity coefficients $\left(K_{A C, J}^{p o t}\right)$ for the two proposed sensors.

\begin{tabular}{|c|c|c|}
\hline Interferent, $J$ & \multicolumn{2}{|c|}{$K_{A C, J}^{p o t}$} \\
\hline & $A C-T P B$ & $A C-P M$ \\
\hline $\mathrm{Na}^{+}$ & $2 \times 10^{-3}$ & $2 \times 10^{-5}$ \\
\hline $\mathrm{K}^{+}$ & $1 \times 10^{-3}$ & $1 \times 10^{-3}$ \\
\hline $\mathrm{Ca}^{2+}$ & $3 \times 10^{-5}$ & $3 \times 10^{-5}$ \\
\hline $\mathrm{Mg}^{{ }^{2+}}$ & $3.5 \times 10^{-5}$ & $3.4 \times 10^{-5}$ \\
\hline $\mathrm{Fe}^{3+}$ & $3 \times 10^{-3}$ & $2.0 \times 10^{-5}$ \\
\hline Glucose & $2 \times 10^{-4}$ & $2 \times 10^{-4}$ \\
\hline Sucrose & $2 \times 10^{-4}$ & $2 \times 10^{-4}$ \\
\hline Lactose & $2 \times 10^{-4}$ & $2 \times 10^{-4}$ \\
\hline Starch & $3 \times 10^{-4}$ & $3 \times 10^{-4}$ \\
\hline Avisil & $1 \times 10^{-4}$ & $1.5 \times 10^{-4}$ \\
\hline gelatin & $1 \times 10^{-4}$ & $1 \times 10^{-4}$ \\
\hline Caffeine & $3 \times 10$ & $3 \times 10$ \\
\hline Tryptophan & $2 \times 10$ & $2 \times 10$ \\
\hline Urea & $1 \times 10^{-5}$ & $1 \times 10^{-3}$ \\
\hline
\end{tabular}

* Organic compounds were studied by mixed solution method

\subsubsection{Precision and Accuracy of the method}

The precision and accuracy of the method were investigated inter-day repeatability by the analysis of $\mathrm{AC}$, five replicate at the limit of quantification range. The precision and accuracy of the method expressed as RSD and \% of deviation of the measured concentration (recovery \%). The results obtained are within the acceptance range of less than $1.5 \%$ and $1.6 \%$. Also reproducibility (day-to day) was investigated. The results indicate an average recovery of 97.8 and $98.5 \%$, relative standard deviation $1.6 \% ; 1.5 \%$ and correlation coefficient of 0.998 and 0.998 respectively for sensor-I and sensor-II.

\subsubsection{Ruggedness}

The ruggedness of the potentiometric method was evaluated by carrying out the analysis using two different analyst (operator) and different instruments on different days. The RSD of less than $2.5 \%$ were observed for repetitive measurements in three different day time periods using two different instruments and operators. The results indicate that the method is capable of producing results with high precision. 


\subsubsection{Robustness}

The robustness of the method was explained by the evaluation the influence of small variation of some of the most important procedure variables including $\mathrm{pH}$, potential range and measuring time. Preliminary inspection of the results under various conditions suggested that the method is fairly robust, but the $\mathrm{pH}$ of the measuring solution should be in the $\mathrm{pH}$ range $2.0-6.0$.

\subsection{Analytical applications}

The reliability of the proposed membrane sensors for the quantification of $\mathrm{AC}$ was examined for direct determination of various concentration of AC (3 - 370.0 $\mu \mathrm{g} / \mathrm{ml})$ using the standard addition "spiking" technique. Results with an average recovery of $99.4 \pm 1.4 \%$ and $99.5 \pm 1.5 \%$ for AC-TPB and AC-PM at $100 \mu \mathrm{g} / \mathrm{ml}(\mathrm{n}=5)$ are obtained. The results are shown in Table 4.

Table. 4. Direct determinations of the percentage recovery of AC using the proposed PVC membrane sensors.

\begin{tabular}{llccc}
\hline $\begin{array}{l}\text { Added } \\
(\mu \mathrm{g} / \mathrm{ml})\end{array}$ & \multicolumn{2}{c}{$\begin{array}{l}\text { Found } \\
(\mu \mathrm{g} / \mathrm{ml})\end{array}$} & \multicolumn{2}{c}{ Recovery, \%* } \\
& $A C-T P B$ & $A C-P M$ & $A C-T P B$ & $A C-P M$ \\
3.0 & 2.93 & 2.93 & $97.6 \pm 1.9$ & $97.6 \pm 1.8$ \\
6.0 & 5.87 & 5.88 & $97.8 \pm 1.8$ & $98.0 \pm 1.8$ \\
10.0 & 9.8 & 9.8 & $98.0 \pm 1.7$ & $99.0 \pm 1.7$ \\
50.0 & 49.0 & 49.5 & $98.0 \pm 1.6$ & $99.0 \pm 1.6$ \\
100.0 & 99.4 & 99.5 & $99.4 \pm 1.5$ & $99.5 \pm 1.5$ \\
200.0 & 198.0 & 199.0 & $99.0 \pm 1.4$ & $99.5 \pm 1.5$ \\
300.0 & 298.0 & 298.0 & $99.3 \pm 1.4$ & $99.3 \pm 1.4$ \\
370.0 & 369.0 & 369.0 & $99.7 \pm 1.4$ & $99.7 \pm 1.4$ \\
\hline
\end{tabular}

Average of 5 measurements \pm RSD.

RSD\%, Relative standard deviation \%

\subsubsection{Determination of AC in Tablets.}

The proposed method has been applied for the determination of AC in Tablet (complete procedure as in section 2.4). The results are summarized in Table 5 including the repeatability data $(\mathrm{n}=5)$. The content of $\mathrm{AC}$ in its formulation using the membrane sensors are with a good agreement with declared amount. The results (Table 5) obtained compare favorably well with the data obtained by British Pharmacopoeia method [23]. Comparison between the experimental means for the two method was carried out using the null hypothesis of $|\mathrm{t}|_{2}$ for $\mathrm{P}=0.05$ and $\mathrm{n}=5$. It was found that $|\mathrm{t}|_{2}=1.3$ and 1.2 for $\mathrm{AC}-\mathrm{TPB}$ and AC-PM, respectively which is less than the tabulated value $\left(|\mathrm{t}|_{2}=3.36\right)$ [24]. No significant difference was found between the two methods, which indicate that the proposed method is accurate as British pharmacopoeia method. Comparison between the precessions of the proposed 
method with the British pharmacopoeia method to estimate the random errors of the two sets of data (Table 5) was also carried out using the two-tailed F-test [24]. From this table it is clear that all the experimental $\mathrm{F}_{4,4}$ values is 1.5 and 1.4 for both AC-TPB and AC-PM, respectively. These values are obviously less than the tabulated value of $\mathrm{F}_{4,4}$ for $\mathrm{P}=0.05$ and $\mathrm{n}=5$ (6.38) [24]. This proves that the results obtained by the two methods are not subject to random errors.

Table 5. Determination of $\mathrm{AC}$ in some pharmaceutical preparations using the proposed PVC membrane sensors.

\begin{tabular}{|c|c|c|c|c|c|c|}
\hline $\begin{array}{l}\text { Drug } \\
\text { (trade }\end{array}$ & $\begin{array}{l}\text { Nominal } \\
\text { value }\end{array}$ & $\begin{array}{r}\text { AC, conten } \\
\quad(\mathrm{mg} / \mathrm{tabl}\end{array}$ & $\begin{array}{l} \pm R S D(\%) \\
\text { t) }(n=5)\end{array}$ & $\begin{array}{c}\text { Official, } * * \\
\text { method }\end{array}$ & $\begin{array}{l}|t|_{2} \\
A C-\end{array}$ & $\begin{array}{l}F \\
A C-\end{array}$ \\
\hline name) & $\begin{array}{l}\text { of } \quad A C, \\
\text { (mg/tablet) }\end{array}$ & $A C-T P B$ & $A C-P M$ & $\begin{array}{l}\text { content } \pm R S D(\%) \\
(m g / \text { tablet })(n=5)\end{array}$ & $T P B(P M)$ & $T P B(P M)$ \\
\hline $\begin{array}{l}\text { Sectral } \\
\text { tablets }\end{array}$ & $200 \mathrm{mg}$ & $197.0 \pm 1.4$ & $198.0 \pm 1.4$ & $197.0 \pm 1.5$ & $1.3(1.2)$ & $1.5(1.4)$ \\
\hline
\end{tabular}

* Average of five determinations

** Aqueous potentiometric method.

\subsubsection{Application of $A C-P V C$ electrodes as indicator electrode.}

The AC sensors were utilized as indicator electrode in conjunction with an $\mathrm{Ag} / \mathrm{AgCl}$ reference electrode for some potentiometric titration. Titration of AC with NaTPB has been performed. Fig.3a and Fig.3b show typical potentiometric titration curves of AC with NaTPB. One mole of AC is consumed per $1 \mathrm{~mol}$ of NaTPB. The inflection break at the equivalence point is about 150 and $120 \mathrm{mV}$ for sensor-I and sensor-II respectively. The equivalence points by all titration curves have been calculated from the titration curve at inflection point and from the first derivative curve.

\section{Experiment}

\subsection{Apparatus}

All potentiometric measurements were made at $25{ }^{\circ} \mathrm{C}$ unless otherwise stated using a WTW $\mathrm{pH} / \mathrm{mV}$ meter (Model 525, Germany) with AC sensor (indicator electrode) in conjunction with a Calomel reference electrode (Model 476350) containing 10\% (w/v) potassium nitrate in the outer compartment. A combined Ross glass $\mathrm{pH}$ electrode (Orin 81-02) was used for all $\mathrm{pH}$ measurements. 


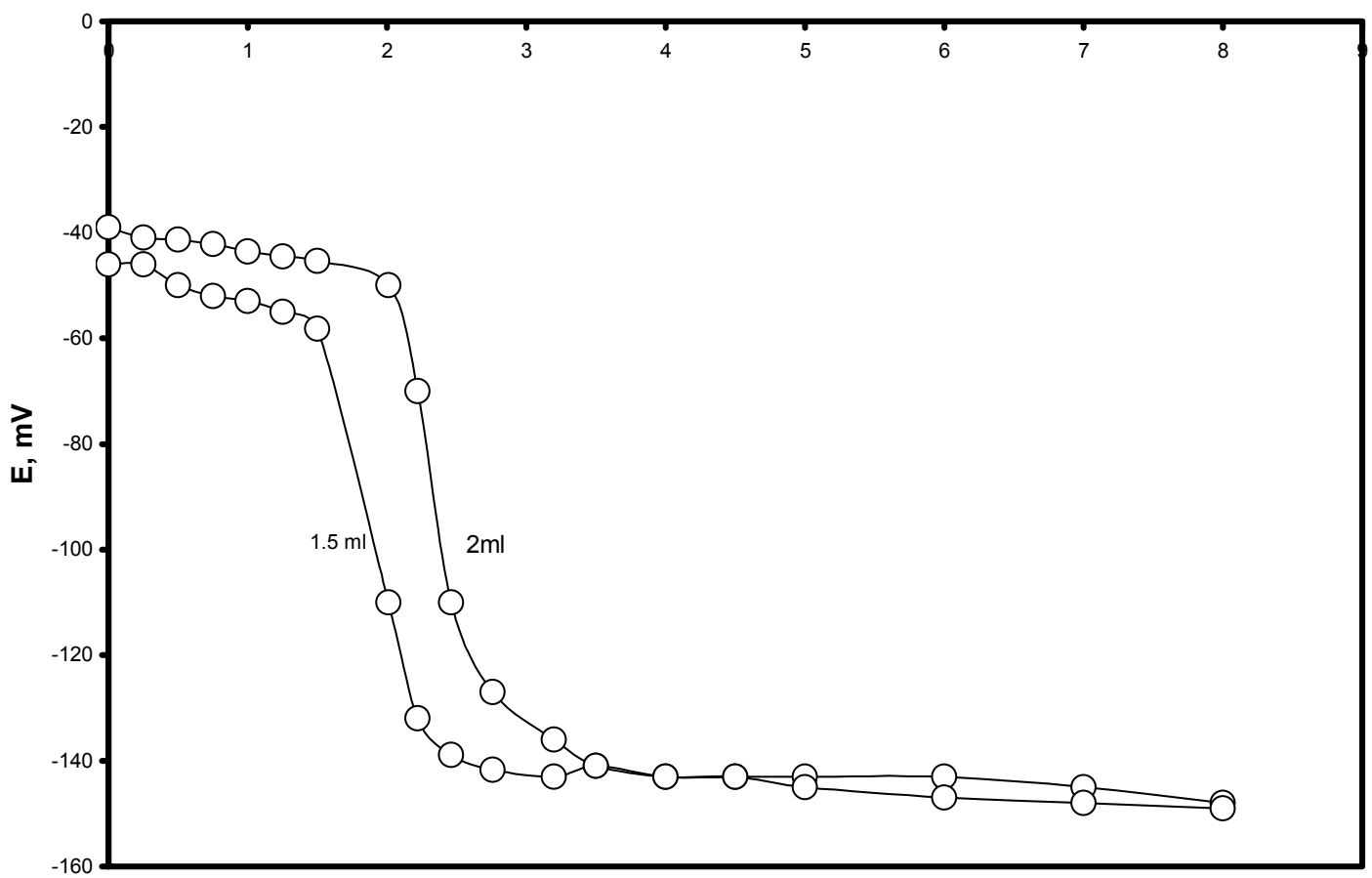

$\mathrm{ml}$ of $0.01 \mathrm{M}$ NaTPB added

Figure 3.a. Typical potentiometric titration curves of 1.5 and $2 \mathrm{ml}$ of $1 \times 10^{-2} \mathrm{M}$ AC with $1 \times 10^{-2} \mathrm{M}$ sodium tetraphenylborate using AC-TPB membrane sensor.

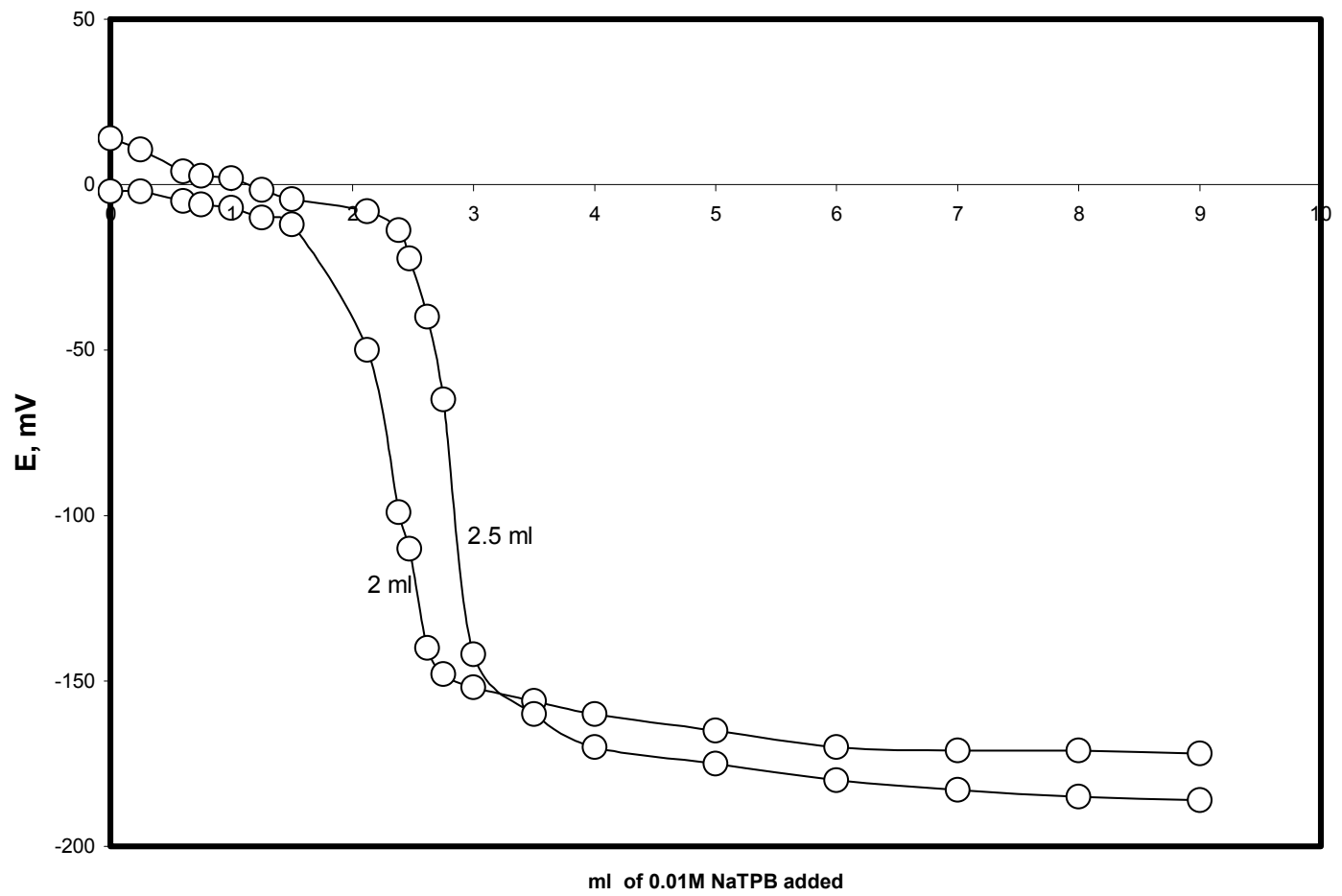

Figure 3.b. Typical potentiometric titration curves of 2 and $2.5 \mathrm{ml}$ of $1 \times 10^{-2} \mathrm{M}$ of $\mathrm{AC}$ with $1 \times 10^{-}$ ${ }^{2} \mathrm{M}$ sodium tetraphenylborate using AC-PM membrane sensor. 


\subsection{Reagents and materials}

All chemicals were of analytical reagent grade unless otherwise stated and doubly distilled water was used throughout. Polyvinyl chloride powder PVC high molecular weight, dioctyl phthalate, dibutyl phthalate, tricresyl phosphate, dibutylsebacate, o-nitrophenyloctyl ether, tetrahydrofurane (THF) of purity $>99 \%$, sodium tetraphenyl borate the preparation of standard solution of NaTPB was prepared by standardization with cetylpyridinium chloride[25], phosphomolybdic acid (PMA) and AC were obtained from Aldrich Chemical Company. AC hydrochloride pure drug was obtained by Sigma and Sectral tablets (labeled $200 \mathrm{mg}$ per tablets) was obtained from Alexandria Co., under license of Rhone Poulenc Rorer, Paris, France. The stock solution of $1 \times 10^{-2} \mathrm{M}$ AC was prepared by dissolving the appropriate amount of $\mathrm{AC}$ in $100 \mathrm{ml}$ of water. Phosphate buffer of $\mathrm{pH} 4.0$ was prepared by mixing $50 \mathrm{ml}$ of $0.1 \mathrm{M} \mathrm{KH}_{2} \mathrm{PO}_{4}$ with appropriate amount of $0.1 \mathrm{M}$ phosphoric acid. The $\mathrm{pH}$ was adjusted to the exact value of $\mathrm{pH} 4.0$.

\subsection{Sensor preparation}

The precipitation of the AC-TPB or AC-PM ion pair were formed by mixing of drop-wise addition of 25 or $75 \mathrm{ml}$ of $1 \times 10^{-2} \mathrm{M}$ solution of $\mathrm{AC}$ to $25 \mathrm{ml}$ of $1 \times 10^{-2} \mathrm{M}$ of NaTPB or PMA respectively with continuously stirred for $10 \mathrm{~min}$. The precipitate was filtered off through a Whatman filter paper No.42, washed with distilled water, dried at room temperature for $24 \mathrm{~h}$ and ground to a fine powder. Elemental analysis confirmed the formation of $1: 1$ and 3:1 complexes of AC-PM and AC-TPB, respectively. A $10 \mathrm{mg}$ portion of the prepared ion association complex was thoroughly mixed in glass Petri dish (5 cm diameter) with $350 \mathrm{mg}$ DOP or DBP or TCP or DBS or o-NPOE, $190 \mathrm{mg}$ PVC powder and $5 \mathrm{ml}$ THF. The Petri dishes were covered with filter paper and left to stand overnight to allow slow evaporation of the solvent and formation of the sensing membrane. The PVC master membrane $(0.1 \mathrm{~mm}$ thick) was obtained, sectioned with a cork borer (10 $\mathrm{mm}$ diameter) and glued to a polyethylene tube ( $3 \mathrm{~cm}$ length, $8 \mathrm{~mm}$ i.d.) using THF as previously described [26, 27]. A laboratory made electrode body was used, which consisted of a glass tube, to which the polyethylene tube is attached at one end and filled with internal reference solution $\left(1 \times 10^{-2} \mathrm{M}\right.$ aqueous $\left.\mathrm{AC} / \mathrm{KCl}\right) . \mathrm{Ag} / \mathrm{AgCl}$ internal reference electrode $(1.0 \mathrm{~mm}$ diameters $)$ was used. The indicator electrode was conditioned by soaking in a $\quad 1 \times 10^{-2} \mathrm{M}$ aqueous $\mathrm{AC}$ solution for $1 \mathrm{~h}$ and stored in the same solution when not in use.

\subsection{Procedure}

The AC-PVC membrane sensors were calibrated by immersion in conjunction with the reference electrode into a $9.0 \mathrm{ml}$ of phosphate buffer of $\mathrm{pH} 4.0$ in a $50 \mathrm{ml}$ beaker. After potential stabilization $\pm 0.5 \mathrm{mV}, 1 \mathrm{ml}$ aliquot of $\mathrm{AC}$ was added with contentious stirring, to give a final AC concentration ranging from $1 \times 10^{-3}-1 \times 10^{-6} \mathrm{M}$; and the potential was recorded. A calibration graph was then constructed by plotting the recorded potential as function of - $\log \mathrm{AC}$ concentration. The resulting graphs (Fig.4) were used for subsequent measurements of unknown AC concentration. . 


\subsection{Determination of AC in Sectral Tablets}

Ten tablets were powdered and a weight equivalent to one tablet (200mg) of acebutolol hydrochloride was transferred quantitatively to $250 \mathrm{ml}$ measuring flask with about $100 \mathrm{ml}$ water and dissolved by applying $5 \mathrm{~min}$ sonication on the ultrasonic bath; thereafter the suspension was diluted to the mark and filtered. $10 \mathrm{ml}$ of the above solution was transferred to $50 \mathrm{ml}$ measuring flask and the $\mathrm{pH}$

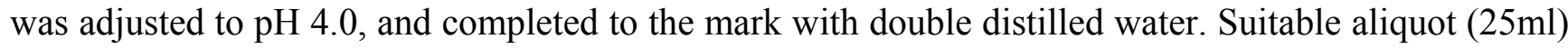
of the above solution was transferred to measuring cell, and the electrode potential was recorded and compared with calibration graph.

Alternatively, the standard addition technique was used for the determination of $\mathrm{AC}$ by monitoring the potential of $\mathrm{AC}$ solution before and after the addition of a known concentration of AC solution $\left(1.0 \mathrm{ml}\right.$ aliquot of $\left.1 \times 10^{-3} \mathrm{M}\right)$. The change in the potential readings was recorded and used to calculate the unknown AC concentration in the test solution using the standard addition technique [21].

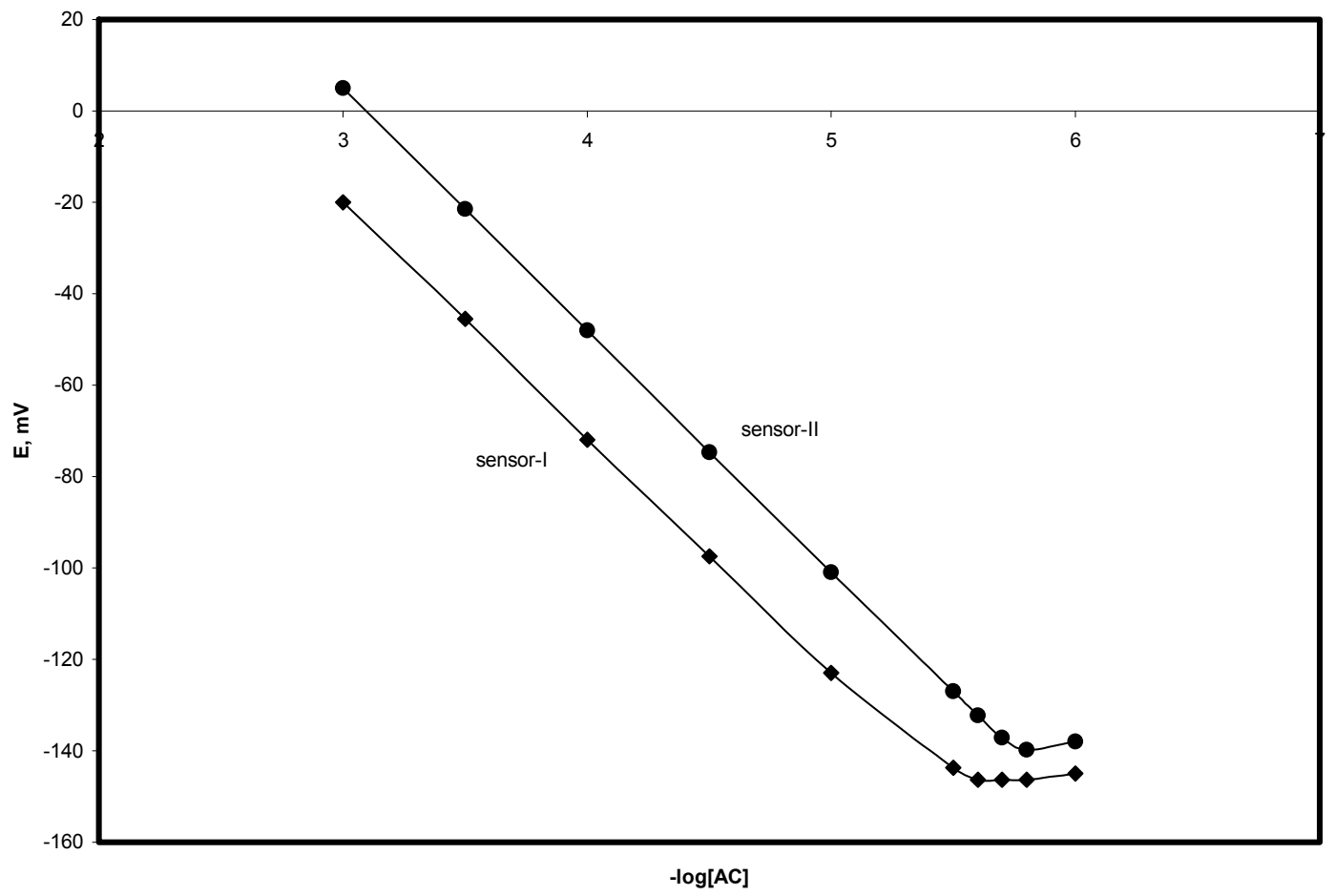

Figure 4. Calibration graph of acebutolol using AC-TPB (sensor-I) and AC-PM (sensor-II).

\section{Conclusion}

In conclusion, the developed PVC membrane sensors described in this work offer a simple, accurate, selective, and specific tool for quantitative determination of $\mathrm{AC}$ in some pharmaceutical formulations. The membrane sensor AC-PM seem to better than AC-TPB with respect to calibration, slop, and accuracy. The PVC sensors have been used as indicator electrode in some potentiometric titrations. The statistical evaluations of the proposed method in comparison with standard official method indicate that the method is accurate and precise. 


\section{References and Notes}

1. Martindal; The Complete Drug Reference, $33^{\text {rd }}$ Ed.; Pharmaceutical Press: London, 2002; pp. 569.

2. Delamoye, M.; Duverneuil, C.; Paraire, F.; de Mazancourt, P.; Alvarez, J.C. Simultaneous determination of thirteen beta-blockers and one metabolite by gradient high-performance liquid chromatography with photodiode-array UV detection. Forensic Science International 2004, 141, 23-31.

3. Saarinen, M.T.; Sirèn, H.; Riekkola, M.-L. Screening and determination of B-blockers, narcotic analgesics and stimulants in urine by high-performance liquid chromatography with column switching. J. Chromatography B.: Biomedical Science and applications 1995, 664, 341-346.

4. Pelander, A.; Ojanpera, I.; Laks, S.; Rasanen, I.; Vuori, E. Toxicological screening with formulabased metabolite identification by liquid chromatography/time-of-flight Mass Spectrometer. Anal. Chem. 2003, 75, 5710-5718.

5. Brunelli, C.; Bicchi, C.; Di Stilo, A.; Salomone, A.; Vincenti, M. High-speed gas chromatography in doping control: fast-GC and fast-GC/MS determination of beta -adrenoceptor ligands and diuretics. J. Sep. Sci. 2006, 29, 2765-2771.

6. Bai, X.; You, T.Y.; Sun, H.; Yang, X.; Wang, E. Determination of three- $\beta$-blockers by capillary electrophoresis with end column electrochemical detection. Electroanalysis 2000, 12, 1379-1382.

7. Sastry, C.S.P.; Rao, S.G.; Naidu, P.Y.; Srinivas, K.R. New spectrophotometric method for the determination of some drugs with iodine and wool fast blue BL. Talanta 1998, 45, 1227-1234.

8. Abdelatef, H.E.; El-Sayed, M.M.; Ayad, H.M. Spectrophotometric and spectrofluorimetric method for acyclovir and acebutolol hydrochloride. Spectrochim. Acta A. Mol. Biomol. Spectrosc. 2006, 65, 996-998.

9. El-Gindy, A.; Ashour, A.; Abdel-Fattah, L.; Shabana, M.M. First derivative spectrophotometric, TLC-densitometric and HPLC determination of acebutolol $\mathrm{HCl}$ in presence of its acid-induced degradation product. J. Pharm. Biomed. Anal. 2001, 24, 527-534.

10. El-Walily, A.F.M. Analysis of nifedipine-acebutolol hydrochloride binary combination in tablets using UV-derivative spectroscopy, capillary gas chromatography and high-performance liquid chromatography. J. Pharm. Biomed. Anal. 1997, 16, 21-30.

11. Nasierowska, Z.; Deres, J.; Suffczynski, J.; Stanczak, W. Polarographic determination of acebutolol. Farm. Pol. 1984, 40, 87-89.

12. Sanbe, H.; Haginaka, J. Restricted access media-molecularly imprinted polymer for propranolol and its application to direct injection analysis of $\beta$-blockers in biological fluids. Analyst 2003, 118, 593-597.

13. Pospišilová, M.; Kavalìrová, A.; Polášek, M. Assay of acebutolol in pharmaceutical by analytical capillary isotachophoresis. J. Chromatogr. A. 2005, 1081, 72-76.

14. Mostafa, G.A.E.; and Ghazy, S.E. Potentiometric PVC membrane sensors for selective determination of pyridoxine hydrochloride (vitamin $\mathrm{B}_{6}$ ) in some pharmaceutical formulations. Annali di Chimica 2003, 93, 691-699.

15. Yuan, J.; Yao, S. A. Sulpha-drug sensitive sensor based on ion-pair complex modified PQC resonator. Talanta 2002, 58, 641-648. 
16. Riahi, S.; Mousavi, M.F.; Bathaie, S.Z.; Shmsipur, M. A novel potentiometric sensor for selective determination of theophylline: Theoretical and practical investigation. Anal. Chim. Acat. 2005, $548,192-198$.

17. Shamsipur, M.; Jalali, F.; Ershad, S. Preparation of a diclofenac potentiometric sensor and its application to pharmaceutical analysis and to drug recovery from biological fluids. J. Pharm. Biomed. Analysis 2005, 37, 943-947.

18. Cunningham, L.; Freiser, H. Ion-selective electrodes for some $\beta$-adeneric and calcium blockers. Anal. Chim. Acta. 1984, 157, 157-162.

19. IUPAC Analytical Chemistry Division. Recommendation for Nomenclature of Ion Selective Electrode. Pure Appl. Chem. 1994, 66, 2527-2536.

20. Anthony, C.M.; M David, O.; Brian W. Clarke's analysis of drugs and poisons, $3^{\text {rd }}$ Ed.; Pharmaceutical Press: Great Britain, 2004; Vol.2, pp.569.

21. Ma, T.S.; Hassan, S.S.M. Organic analysis using ion selective electrodes. Academic press: London, 1982; Vol. 1\&2.

22. IUPAC Analytical Chemistry Division. Potentiometric selectivity coefficients of ion selective electrodes. Pure Appl. Chem. 2000, 72, 1851-185.

23. British Pharmacopoeia; The Stationery Office: London, 2003; pp. 36, 52.

24. Miller, J.C.; Miller, J.N. Statistics for analytical chemistry, $1^{\text {st }}$ Ed.; Ellis Harwood Limited: England, 1986; pp. 43, 53, 59, 189, 192.

25. British Pharmacopoeia; The Stationery Office: London, 1980; volume II appendix 1B, A45.

26. Hassan, S.S.M.; Marzouk, S.A.M. A novel ferroin membrane sensor for potentiometric determination of iron. Talanta 1994, 41, 891-899.

27. Carggs, A.; Moody, G.J.; Tomas, J.D.R. PVC matrix membrane ion-selective electrodes. J. Chem. Educ. 1974, 51, 541-544.

(C) 2007 by MDPI (http://www.mdpi.org). Reproduction is permitted for noncommercial purposes. 